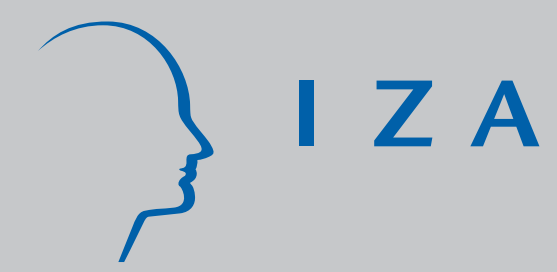

IZA DP No. 1784

'Taxing' Doctors: The Impact of Income Caps on the Provision of Medical Services

\author{
Boris Kralj \\ J asmin Kantarevic \\ Darrel Weinkauf \\ September 2005
}




\title{
'Taxing' Doctors: \\ The Impact of Income Caps on the Provision of Medical Services
}

\author{
Boris Kralj \\ Ontario Medical Association \\ Jasmin Kantarevic \\ Ontario Medical Association \\ and IZA Bonn \\ Darrel Weinkauf \\ Ontario Medical Association
}

Discussion Paper No. 1784

September 2005

IZA
P.O. Box 7240
53072 Bonn
Germany

Phone: +49-228-3894-0

Fax: +49-228-3894-180

Email: iza@iza.org

Any opinions expressed here are those of the author(s) and not those of the institute. Research disseminated by IZA may include views on policy, but the institute itself takes no institutional policy positions.

The Institute for the Study of Labor (IZA) in Bonn is a local and virtual international research center and a place of communication between science, politics and business. IZA is an independent nonprofit company supported by Deutsche Post World Net. The center is associated with the University of Bonn and offers a stimulating research environment through its research networks, research support, and visitors and doctoral programs. IZA engages in (i) original and internationally competitive research in all fields of labor economics, (ii) development of policy concepts, and (iii) dissemination of research results and concepts to the interested public.

IZA Discussion Papers often represent preliminary work and are circulated to encourage discussion. Citation of such a paper should account for its provisional character. A revised version may be available directly from the author. 
IZA Discussion Paper No. 1784

September 2005

\section{ABSTRACT \\ 'Taxing' Doctors: \\ The Impact of Income Caps on the Provision of Medical Services}

Income cap or threshold systems rely on incentives that encourage physicians to limit medical expenditures, but little is known about how physicians respond to these incentives. Conceptually, the threshold system is to physicians what an income tax system is to taxpayers. We exploit this similarity to analyze the impact of a reform that changed what is included in the 'taxable' billings of physicians in Ontario, Canada. We find that for services that the reform turned from exempted to non-exempted, the reform had a strong, negative impact for physicians with billings above the minimum threshold and a negligible impact for physicians below the threshold. The reform had no impact on services that were nonexempted both before and after the reform. This response of physicians to the threshold reform resembles the expected response of taxpayers to a similar change in the income tax system.

JEL Classification: I10, I18

Keywords: physicians' behavior, income thresholds, non-convex budget sets

Corresponding author:

Jasmin Kantarevic

Ontario Medical Association

525 University Ave., Suite 300

Toronto, ON, M5G 2K7

Canada

Email: jasmin_kantarevic@oma.org 


\section{Introduction}

In Ontario, as in other Canadian provinces, health insurance coverage is universal and physicians are compensated directly by the provincial government for providing insured services. As the sole payer for physicians' services, the government has considerable capacity to influence what physicians do and how much they bill, and thereby to better manage its expenditures on health care. Policies aimed to control health care expenditures have the promise of reducing budget deficits, improving use of public funds, and increasing overall efficiency of health care system. However, many policies devised by the government in this context are controversial and there is little systematic evidence to guide the heated debate.

One of the most controversial of these policies is the so called threshold system, introduced in Ontario in 1991. The threshold system is to physicians what an income tax system is to taxpayers: it determines the composition of medical services included in the 'taxable' billings of physicians; it defines the number of 'tax' brackets and their threshold amounts; and it specifies the 'tax' rate applied to each bracket. The threshold system therefore has the potential to influence physicians' behavior in a similar way that the income tax system influences labor supply behavior of individuals and their earnings. In contrast to the income tax system, however, there has been little analysis of the threshold system ${ }^{1}$.

In this paper, we analyze the impact of the threshold system on the composition of services provided by physicians in Ontario. Specifically, we study the 1998 reform that turned a large number of medical services from exempted to non-exempted, and we examine whether physicians responded to the reform by changing the types of services they provide. Our study is directly relevant to health policy makers in all Canadian provinces. Three provinces - British Columbia, Prince Edward Island, and Quebec - currently employ threshold systems, while the remaining provinces employed threshold systems at some point in the $1990 \mathrm{~s}^{2}$. More generally, the study contributes to our understanding of whether physicians respond to financial incentives in the threshold system in a similar way that taxpayers respond to incentives in income tax systems. Our findings are also relevant to health maintenance organizations (HMOs) in the United States. Many HMOs operate on

\footnotetext{
${ }^{1}$ Hausman (1981) surveys studies of the impact of progressive income tax programs on labour supply. See also Moffitt (1986) and (1990) and Heim and Meyer (2003).

${ }^{2}$ In Ontario, the threshold system was eliminated on April 1, 2005.
} 
global budgets and physicians' fees are reduced if their expenditures exceed the budgeted amounts. These financial incentives resemble features of the physician threshold system in Canada, but little is known about whether physicians respond to these incentives ${ }^{3}$.

The 1998 reform is attractive to analyze because it affected a large number of medical services and physicians in many medical specialties, thereby increasing the probability to detect a reform impact. The second advantage of analyzing the 1998 reform is that the reform did not alter any other elements of the system, such as the number of 'tax' brackets or thresholdspecific 'tax' rates. Consequently, we can derive tight predictions about the expected impact of the 1998 reform, and with more confidence attribute the estimated impact to a single factor, holding other parameters of the system constant.

To derive these predictions, we utilize a model of labor supply with nonconvex budget set that has been used successfully in studies of income tax systems ${ }^{4}$. The main implication of the model is that the expected impact of the 1998 reform depends on whether physician's billings before the reform were below or above the minimum threshold level using the new system rules. Specifically, we identify three groups of physicians that were 'treated' differentially by the 1998 reform: a group that should not be affected by the reform, a group that will substitute away from services exempted from the system to non-exempted services, and a group for whom the reform impact depends on empirical magnitudes of various parameters of the model.

We use the Ontario Health Insurance Plan (OHIP) data to evaluate these predictions. The OHIP data includes all fee-for-service physicians in Ontario, a group that forms the entire population of physicians affected by the threshold system. The data also includes detailed information on all medical services provided by each fee-for-service physician on a daily basis that is necessary to precisely assign physicians to the three treatment groups.

Our basic approach to identify the impact of the 1998 reform is to compare medical services provided by physicians in each treatment group before and after the reform, and to attribute the change in medical services to the

\footnotetext{
${ }^{3}$ Gaynor, Rebitzer, and Taylor (2001) and (2004) are two outstanding exceptions. The authors also address the issue of team incentives and moral hazard because the HMO contracts are often based on performance of panels of physicians rather than individual doctors. These issues are absent in the Canadian context since the threshold system applies to individual physicians.

${ }^{4}$ See Hausman (1985), Moffitt (1986) and (1990), and Heim and Meyer (2003).
} 
1998 reform. We control for differences among physicians in age, gender, medical specialty, and geographic location of their practice. In addition, we use physicians with the Service Retention Initiative (SRI) status who are exempted from the threshold system altogether as our control group to account for variables that can potentially affect the provision of medical services in addition to the 1998 reform, such as various government policies and shocks to the physicians' labor market. Furthermore, we account for the potential composition bias because the reform affected incentives of physicians to switch to the SRI control group and thus be exempted from the threshold system. Lastly, we instrument for the assignment of physicians to the treatment groups to account for potential measurement errors and non-random assignment of physicians to the treatment groups.

Our findings are as follows. First, the 1998 reform had a negligible impact on the provision of initially exempted services by physicians whose billings before the reform were below the minimum threshold using both the old and the new system rules. Second, the reform had a negative impact on the provision of initially exempted services by physicians in the other two groups those whose billings before the reform exceeded the minimum threshold using the new system rules. Third, the reform had no impact on the provision of services that were non-exempted both before and after the reform, by all groups of physicians. These findings confirm that physicians respond to financial incentives in the threshold system and that their response resembles the response of taxpayers to similar changes in the income tax system.

\section{Threshold System in Ontario}

The introduction of the threshold system in Ontario can be explained in large part by two factors. First, health care expenditures, the largest item on the government expenditures list, increased by over 200 percent in real terms from 1980 to $1990^{5}$. Second, the economic recession of the $1980 \mathrm{~s}$ slowed down the growth in government revenues. In its efforts to balance the budget, the government introduced a number of policies aimed at limiting increases in overall expenditures. An attractive target of these policies was the physicians' compensation - one of the fastest growing components of health care expenditures.

\footnotetext{
${ }^{5}$ See "National Health Expenditures Trends 1975-2004", Canadian Institute for Health Information (2004).
} 
For similar reasons, the threshold system was introduced in all Canadian provinces in the 1990s. Three provinces still use the system - British Columbia, Prince Edward Island, and Quebec. The rest of provinces abandoned the system, but they still employ many policies with the same general purpose of controlling physicians' payments ${ }^{6}$.

The threshold system closely resembles a progressive income tax system. In an income tax system, the tax is based on each person's taxable income, which includes income obtained from various sources minus any exemptions and deductions. The income tax system usually defines a number of taxable income intervals, with a specific marginal tax rate for each interval. The system is called progressive when these marginal tax rates increase with levels of taxable income, as is the case in most countries.

The similarities between the progressive income tax system and the threshold system can be seen in Appendix Table 1. When the threshold system was introduced in Ontario in 1991, physicians were 'taxed' at a rate of one third if their 'taxable' billings exceeded $\$ 400,000$, and at a rate of two-thirds if their 'taxable' billings exceeded $\$ 475,000$. Included in the 'taxable' billings were all medical services rendered by physicians. Physicians practicing in under-served areas and in unique medical sub-specialties were exempted from the system under a program known as the Service Retention Initiative (SRI) program. The SRI program was intended to partially offset the effect of the threshold system by discouraging specialists from leaving the province and to redress geographical mal-distribution of physicians.

In the following four years, the $\$ 400,000$ and $\$ 475,000$ thresholds increased in parallel with the average increase in medical fees. A major reform in the system occurred in 1996, when the government made thresholds specific to each medical specialty and at levels significantly lower than in the previous years. The government also identified services to be exempted from the system, using criteria that included services urgently requiring protection, services with high potential to be discontinued or where shortages currently exist.

The provisions of the 1996 reform were partially reversed over the following two years. By the end of 1996, a new system abandoned thresholds specific to each medical specialty and instead differentiated between general practitioners and specialists only. Another major reform occurred in 1998 -

\footnotetext{
${ }^{6}$ For more details on the threshold system in Ontario and other Canadian provinces, see Dowdall and Ramchandar (1999).
} 
the reform on which we focus in this study - when most services exempted by the 1996 reform were now included in the 'taxable' billings ${ }^{7}$.

Over the next four years the system remained stable, with increases in thresholds matching average increases in medical fees. The latest significant reform occurred in 2002 when government imposed a single threshold for all medical specialties and exempted certain hospital and critical care services from the system. Lastly, the threshold system was eliminated on April 1, 2005 by the new four-year agreement between the Ontario Ministry of Health and Long-Term Care and Ontario physicians.

The threshold system has thus undergone many reforms since its introduction in 1991. These reforms provide an opportunity to evaluate the impact of parameters of the system on various outcomes of interest, such as the total billings of physicians and the composition of medical services provided by physicians. In this study we choose to focus on the 1998 reform for two reasons. First, it is the reform that affected only one parameter of the threshold system (namely, the composition of services included in the 'taxable' billings). Therefore, we can derive more precisely the expected impact of the reform, and also with more confidence attribute the estimated impact to a single source, holding other parameters of the system constant. Second, the 1998 reform affected a large number of medical services, including transplants, surgery, audiology, angioplasty, obstetrics, pacemakers, dialysis, and radiation oncology. In 1997, the total value of the exempted services affected by the 1998 reform represented about $3 \%$ of the value of all medical services provided by fee-for-service physicians (about CAD $\$ 150$ million), and about one third of physicians provided some exempted services. Such large exposure to the 1998 reform, in comparison to reforms in other years that also affected what is included in the 'taxable' billings, improves our chances to detect an impact of the reform in our data.

\section{Expected Impact of the 1998 Reform}

To analyze the impact of the 1998 reform on the provision of medical services by physicians, we utilize a simple stylized model of labor supply with nonlinear budget constraint that has been used extensively in studies of the

\footnotetext{
${ }^{7}$ For details about the 1998 reform, see Ontario Health Insurance Plan Bulletin Number 4309.
} 
income tax system ${ }^{8}$. We start by describing the optimal choices of physicians when some services are exempted from the threshold system while other services are not. This case corresponds to the situation before the 1998 reform. We then examine optimal choices of physicians when all services are non-exempted, as was the case after the 1998 reform was put into action.

\subsection{Model with Exempted and Non-Exempted Ser- vices}

Consider a representative physician who maximizes a strictly quasi-concave utility function $u(c, l)$, where $c$ represents the composite consumption good and $l$ represents hours of leisure (or any activity other than work). The price of consumption good is normalized to one.

The physician faces three types of constraints: the budget constraint, the technology constraint, and the time constraint.

The budget constraint states that the physician's expenditures on the consumption good cannot be larger than his total income, which is the sum of income derived from the medical practice and income derived from other sources (also called non-labor or virtual income, and denoted by $m$ ). Income derived from the medical practice consists of revenues obtained from providing two types of medical services, $x_{1}$ and $x_{2}$. The relative price of $x_{1}$ is $p_{1}$, and the relative price of $x_{2}$ is $p_{2}$. The difference between $x_{1}$ and $x_{2}$ is that the revenues obtained from $x_{2}$ are exempted from the 'taxable' billings, while the revenues from $x_{1}$ are not. Specifically, if revenues obtained from providing $x_{1}$ do not exceed the threshold, denoted by $\bar{y}$, then the physician receives the full value of services provided; and if revenues obtained from providing $x_{1}$ exceed the threshold, then the physician receives only $(1-t)$ of the value of $x_{1}$ services provided above the threshold, where $t \in[0,1]$ is the reduction rate $^{9}$. The budget constraint can therefore be written as:

$$
\begin{array}{rr}
c=p_{1} x_{1}+p_{2} x_{2}+m & \text { if } p_{1} x_{1} \leq \bar{y} \\
c=p_{1}^{\prime} x_{1}+p_{2} x_{2}+m^{\prime} & \text { if } p_{1} x_{1}>\bar{y}
\end{array}
$$

where $p_{1}^{\prime} \equiv(1-t) p_{1}$ and $m^{\prime} \equiv t \bar{y}+m$.

\footnotetext{
${ }^{8}$ See Hausman (1985), Moffitt (1986), Moffitt (1990), and Heim and Meyer (2003).

${ }^{9}$ The assumption of one threshold is simplification; in 1997, the system had three thresholds with marginal reduction rates of $1 / 3,2 / 3$, and $3 / 4$.
} 
The technology constraint states that $x_{1}$ and $x_{2}$ can be produced according to the following production functions:

$$
x_{1}=x_{1}\left(h_{1}\right), \quad x_{2}=x_{2}\left(h_{2}\right)
$$

where $h_{1}$ and $h_{2}$ are hours of work dedicated to services $x_{1}$ and $x_{2}$, and functions $x_{1}($.$) and x_{2}($.$) are assumed to be strictly increasing and concave { }^{10}$.

Lastly, the physician can allocate his total time, denoted by $T$, between leisure and between work on $x_{1}$ and $x_{2}$, so the time constraint can be written as:

$$
T=h_{1}+h_{2}+l
$$

Since the utility function is strictly concave and the budget set is convex, it follows that there exists a unique global maximum to the physician's problem. To find this maximum we can use a simple algorithm ${ }^{11}$. Start with the first segment of the budget set defined in (1a) and compute $h^{a}=\left(h_{1}^{a}, h_{2}^{a}\right)$ that maximizes $u(c, l)$ subject to $(1 a),(2)$, and (3). If $h^{a}$ is feasible, in the sense that $p_{1} h_{1}^{a}<\bar{y}$, then $h^{a}$ is the unique global maximum. If $h^{a}$ is not feasible, move to the second segment of the budget set defined in $(1 b)$ and compute $h^{b}=\left(h_{1}^{b}, h_{2}^{b}\right)$ that maximizes $u(c, l)$ subject to $(1 b),(2)$, and (3). If $h^{b}$ is feasible, so that $p_{1} h_{1}^{b}>\bar{y}$, then $h^{b}$ is the unique global maximum. If $h^{b}$ is not feasible, then a point on the kink of the budget set is optimal, since neither $h^{a}$ or $h^{b}$ is feasible. Given $h_{1}$ and $h_{2}$ that solve the physician's problem, we can then use (2) to find the optimal supply of services $x_{1}$ and $x_{2}$.

\footnotetext{
${ }^{10}$ Physicians may, of course, become more efficient as they provide more services, because of learning-by-doing, gains to specialization, etc. However, other inputs into the production of medical services, such as operating room time, nurses, technology, etc., are most likely to be fixed, at least in the short run. This provides partial justification for the concavity assumption. Our comparative static results do not depend on the concavity of production functions, but relaxing it in favor of increasing returns to scale may affect the existence and uniqueness of the solution to the physician's maximization problem.

${ }^{11}$ We assume that providing no services is never optimal because all physicians in our data provide some non-exempted services and some physicians also provide exempted services.
} 


\subsection{Reform That Eliminates Exempted Services}

Consider now the case in which $x_{2}$ services are no longer exempted from the threshold system, as was the case after the 1998 reform. In this case, the original budget constraint in $(1 a)$ and $(1 b)$ is modified as follows:

$$
\begin{array}{ll}
c=p_{1} x_{1}+p_{2} x_{2}+m & \text { if } p_{1} x_{1}+p_{2} x_{2} \leq \bar{y} \\
c=p_{1}^{\prime} x_{1}+p_{2}^{\prime} x_{2}+m^{\prime} & \text { if } p_{1} x_{1}+p_{2} x_{2}>\bar{y}
\end{array}
$$

where $p_{2}^{\prime} \equiv(1-t) p_{2}$ and all other notation is as before.

There are two main differences between the old and the new threshold system. First, $x_{2}$ is now taxed at the rate $t$ if total billings exceed the threshold. Second, the revenues from $x_{2}$ are now included in the 'taxable' billings, which determines what is feasible for each segment of the budget set. This is illustrated in Figure 1. In the old threshold system, the area $C$ represents all pairs of $x_{1}$ and $x_{2}$ for which total billings exceed the threshold, while the areas $A$ and $B$ represent all $\left(x_{1}, x_{2}\right)$ pairs for which total billings fall below the threshold. In the new system, the area $A$ represents all pairs of $x_{1}$ and $x_{2}$ for which total billings are below the threshold, while the areas $B$ and $C$ are all $\left(x_{1}, x_{2}\right)$ pairs for which total billings exceed the threshold.

The impact of the 1998 reform, which changed the status of $x_{2}$ services from exempted to non-exempted, depends on which area in Figure 1 physicians were located in before the reform.

Consider first physicians who were located in area $A$. The 1998 reform should have no impact on this group of physicians because their utilitymaximizing choice of $\left(x_{1}, x_{2}\right)$ pair is feasible in both the old and the new system.

Consider next physicians who were located in area $B$. Their utility-maximizing choice of $\left(x_{1}, x_{2}\right)$ pair was feasible in the old system, but it is no longer feasible after the reform. Let $x=\left(x_{1}\left(p_{1}, p_{2}, m\right), x_{2}\left(p_{1}, p_{2}, m\right)\right)$ denote the optimum for these physicians in the old system, and let $\hat{x}=\left(\hat{x}_{1}\left(p_{1}^{\prime}, p_{2}^{\prime}, m^{\prime}\right), \hat{x}_{2}\left(p_{1}^{\prime}, p_{2}^{\prime}, m^{\prime}\right)\right)$ denote their optimum after the reform ${ }^{12}$. Using the first-order Taylor approximation, we have:

\footnotetext{
${ }^{12}$ The new optimum for these physicians cannot be in the area $A$, because if it were, it would also be the optimum in the old system. Therefore, the new optimum is in the area $B$ or $C$, with prices $p_{1}^{\prime}$ and $p_{2}^{\prime}$ and virtual income $m^{\prime}$.
} 


$$
\begin{aligned}
& \hat{x}_{1}-x_{1}=-t h_{1}\left(\partial x_{1} / \partial h_{1}\right)\left[\varepsilon_{11}+\varepsilon_{12}-\varepsilon_{1 m} \bar{y} / m\right] \\
& \hat{x}_{2}-x_{2}=-t h_{2}\left(\partial x_{2} / \partial h_{2}\right)\left[\varepsilon_{21}+\varepsilon_{22}-\varepsilon_{2 m} \bar{y} / m\right]
\end{aligned}
$$

where $\varepsilon_{i k}$ is the own-price elasticity of hours of work dedicated to service $i$ if $i=k$ and $\varepsilon_{i k}$ is the cross-price elasticity of hours of work dedicated to service $i$ if $i \neq k$, and $\varepsilon_{i m}$ is the income elasticity of hours of work dedicated to service $i$, for $i, k=1,2$.

In the regular case, the own-price elasticity of hours of work is positive, while the cross-price elasticity and the income elasticity are negative. In this case, the expressions in the equation (4) could be of either sign or even zero, and the impact of the 1998 reform on the supply of exempted and non-exempted services remains an empirical question. The ambiguity arises because the reform affects both prices and non-labor income. For example, the decline in the price of $x_{1}$ and the increase in non-labor income induce physicians to decrease their supply of $x_{1}$ services, but the decline in the price of $x_{2}$ provides a conflicting incentive to increase the supply of $x_{1}$ services. When the cross-price elasticity is small in absolute value, the expected impact of the reform is to decrease the provision of both $x_{1}$ and $x_{2}$ services.

Lastly, consider physicians who were located in area $C$. Their choice of $\left(x_{1}, x_{2}\right)$ in the old system is still feasible in the new system, but it is no longer utility-maximizing because $x_{2}$ services are now taxed at the rate t. As before, let $x=\left(x_{1}\left(p_{1}^{\prime}, p_{2}, m^{\prime}\right), x_{2}\left(p_{1}^{\prime}, p_{2}, m^{\prime}\right)\right)$ denote the optimum for these physicians in the old system, and let $\hat{x}=\left(\hat{x}_{1}\left(p_{1}^{\prime}, p_{2}^{\prime}, m^{\prime}\right), \hat{x}_{2}\left(p_{1}^{\prime}, p_{2}^{\prime}, m^{\prime}\right)\right)$ denote their optimum after the reform ${ }^{13}$. Using the Taylor approximation as before we have:

$$
\begin{aligned}
& \hat{x}_{1}-x_{1}=-t h_{1}\left(\partial x_{1} / \partial h_{1}\right) \varepsilon_{12} \\
& \hat{x}_{2}-x_{2}=-t h_{2}\left(\partial x_{2} / \partial h_{2}\right) \varepsilon_{22}
\end{aligned}
$$

In the regular case in which the own-price elasticity of hours of work is positive and the cross-price elasticity is negative, the reform is expected to induce physicians to reduce their supply of $x_{2}$ services and to increase their supply of $x_{1}$ services. The result is unambiguous because the only change

\footnotetext{
${ }^{13}$ As before, the new optimum for these physicians cannot be in the area $A$, because if it were, it would also be the optimum in the old system.
} 
caused by the reform is the decline in the price of $x_{2}$, inducing physicians to substitute away from exempted to non-exempted services.

We summarize our discussion so far and gather the empirical implications of the model in Proposition 1.

\section{Proposition 1}

1. Physicians whose 'taxable' billings before the 1998 reform were below the threshold using both the old and the new system rules (those located in area $A$ in Figure 1) should not be affected by the reform.

2. Physicians whose 'taxable' billings before the 1998 reform were above the threshold using both the old and the new system rules (those located in area $C$ in Figure 1) are expected to decrease their supply of initially exempted services and increase their supply of non-exempted services.

3. The impact of the 1998 reform on physicians whose 'taxable' billings before the reform were below the threshold using the old system rules but would be above the threshold using the new system rules (those located in area $B$ in Figure 1) depends on four factors: (i) the own-price elasticity of hours of work, (ii) the cross-price elasticity of hours of work, (iii) the income elasticity of hours of work, and (iv) the ratio of threshold level to non-labor income. Specifically, physicians are more likely to reduce their supply of both non-exempted services and initially exempted services the larger are, in absolute value, (i), (iii), and (iv), and the smaller is (ii).

\section{Data}

To examine the empirical implications stated in Proposition 1, we use the Ontario Health Insurance Plan (OHIP) data for the fiscal years 1997 and 1998. The 1998 reform was announced and became effective in the first month of the fiscal year 1998, so our sample includes one year before the reform and one year after the reform. As discussed earlier, the only difference in the threshold system between these two years is that some services were exempted in 1997 but not in 1998 .

The OHIP data has several advantages for analyzing the 1998 reform. First, the data includes all fee-for-service physicians in Ontario, a group that 
forms the entire population of physicians affected by the threshold system. Salaried physicians and physicians paid under alternative payment plans were not subject to the threshold system and are not included in our data. Second, the data includes detailed information on medical services, such as the specific fee code of the service and the amount billed for it by each fee-for-service physician on a daily basis. Such information is necessary to precisely assign physicians to three groups - $A, B$, and $C$ - that are 'treated' by the 1998 reform. The data also includes basic information about physicians, such as their age, gender, medical specialty, and the geographic location of practice. The third advantage of the OHIP data is that it includes information on the SRI status of physicians. The SRI physicians are paid on the fee-for-service basis, but should not be affected by the reform because of their exemption from the threshold system. The SRI physicians are therefore a promising control group that can be used to identify the impact of the 1998 reform.

We assign physicians to the three treatment groups as follows. Based on the type and number of services provided in 1997, we calculate the 'taxable' billings of physicians using both the old (1997) and the new (1998) system rules. If the 'taxable' billings calculated using the old and the new rules does not exceed the minimum threshold level, a physician is assigned to group A; if the 'taxable' billings calculated using the old rules do not exceed the minimum threshold level, but exceed the minimum threshold level using the new rules, a physician is assigned to group B; and if the 'taxable' billings calculated using the old and the new rules exceed the minimum threshold level a physician is assigned to group $\mathrm{C}$.

We also experiment with assigning physicians to the three treatment groups based on the number and type of medical services provided in the fiscal year 1996. The benefit of assigning physicians using the billings in 1996 rather that in 1997 is that we can better address two potential threats to our identification strategy: the imprecise assignment of physicians to the treatment groups, and the endogenous sorting of physicians between the treatment groups, as we will discuss in more detail in the next section.

Lastly, we assign physicians with the SRI status - in either 1997 or 1998 to the SRI control group. As a robustness check, we also experiment with assigning physicians to the SRI group based on their 1997 status only and with distinguishing between the SRI physicians whose practices are fully exempted from the system and those whose practices are only partially exempted ${ }^{14}$.

\footnotetext{
${ }^{14}$ The partial SRI exemption applies only to selected services and locations, while the
} 
Our data contains a significant number of physicians who provided no exempted services in either 1997 or 1998 (about 70\% of all physicians). Conceptually, these physicians are either potential providers of exempted services or they are non-providers. The potential providers are physicians who can provide exempted services but choose not to do so because of insufficient financial incentives, while the non-providers are physicians who cannot provide exempted services because they lack required knowledge, equipment, etc. The non-providers are therefore significantly different from the rest of physicians (providers and potential providers), and it is desirable to exclude them from the sample whenever they can be identified. Throughout most of our analysis we therefore limit our sample to physicians who provided some exempted services in at least one year during the period 1992 to 2004 . This criterion should include most potential providers but exclude non-providers because the financial incentives to provide exempted services varied largely over the 13-year period. As a specification check, we also use the entire sample of physicians but utilize statistical models developed in the literature to account for excess zeros in count dependent variables (the zero-inflated models and the two-part model ${ }^{15}$ ).

Our final sample includes 6,203 physicians (12,406 physician-year observations). The descriptive statistics of the sample are presented in Table 1. Consider physicians' characteristics first. In 1997, physicians in group $A$ were on average one year older than physicians in the other groups. Group $A$ is also the group with the largest percentage of female physicians. Most physicians in groups $B$ and $S R I$ are specialists, while most physicians in groups $A$ and $C$ are general practitioners. Lastly, less than one-third of physicians in each group practice in the Toronto planning region. The physicians' characteristics in 1998 are very similar to those in 1997, except that the percentage of specialists in the SRI group increased from $66 \%$ to $85 \%$. We explore this compositional change later in this section.

Consider next the provision of medical services per physician. Physicians in group $C$ provided on average the largest number of non-exempted services, followed by the SRI physicians and physicians in the groups $B$ and $A$. This ranking is identical in both 1997 and 1998, and it is as expected because physicians in group $C$ have the highest total billings, most of which are

full SRI exemption applies to all services and locations.

${ }^{15}$ For discussion of these models, see Greene (1994), Grootendorst (1995), and Jones (2000). 
billings for non-exempted medical services. In contrast, physicians in group $B$ provided on average the largest number of services exempted in 1997 but non-exempted in 1998, followed by the $S R I$ physicians, and then physicians in the groups $C$ and $A$. Again, this ranking is identical in both 1997 and 1998. The ranking is also as expected, because 'taxable' billings of physicians in group $B$ would be above the threshold if the 1998 rules were used mainly because of their high supply of exempted services.

In Table 2, we examine the percentage changes in the provision of medical services per physician between 1997 and 1998, by the exemption type of service and for each group of physicians. Consider the upper panel of Table 2 first. For physicians in group $A$, the percentage change for both exempted and non-exempted services is relatively small ( $-6 \%$ and $-4 \%$, respectively). In contrast, the number of exempted services per physician fell significantly for physicians in groups $B$ and $C$ (by $-34 \%$ and $-36 \%$, respectively), with small change in the number of non-exempted services per physician $(-1 \%$ and $-7 \%$, respectively). Lastly, the SRI physicians have significantly increased their provision of exempted services (by 69\%) and decreased their provision of non-exempted services (by -20\%).

These percentage changes are largely consistent with the empirical predictions stated in Proposition 1. They indicate little change for physicians in group $A$ for both types of services; a negative impact on exempted services for physicians in group $C$, although without predicted substitution toward nonexempted services; and a negative impact on exempted services for physicians in group $B$, which is consistent with strong own-price and income elasticities of hours of work and a weak cross-price elasticity.

However, these results may not represent the impact of the 1998 reform because physicians most affected by the reform (physicians in group $B$ ) had strong incentives to switch to the SRI group and thus be exempted from the threshold system altogether ${ }^{16}$. If these physicians had an above average

\footnotetext{
${ }^{16}$ The switch to the SRI group is not automatic, however, as physicians have to meet the SRI eligibility criteria established by the Ministry of Health and Long-Term Care. For most physicians, it is practically impossible to change their medical sub-specialty in a single year to meet the criteria. In addition, for many physicians the financial and adjustment costs of moving to an under-served area may outweigh the benefits of obtaining the SRI status. Therefore, the increase in the number of SRI physicians in 1998 can hardly be explained by the change in either of these two factors. Instead, the new SRI physicians were applicants who expected to exceed the threshold in 1998 because of the reform and their eligibility was determined by the Ministry on a case-by-case basis.
} 
provision of exempted services, then their move to the $S R I$ group can explain both the significant drop for group $B$ and the significant increase for the $S R I$ group. In other words, the decline in the exempted services for group $B$ could be entirely due to a compositional change and not to a genuine change in behavior. Indeed, if we examine the change in the number of physicians in groups $B$ and $S R I$, the composition bias seems to be a real concern: the number of physicians in group $B$ decreased by 30\% (from 321 in 1997 to 224 in 1998), while the number of SRI physicians increased by 191\% (from 89 to 259).

To address this concern, we utilize two methods commonly employed in the literature to account for the composition bias ${ }^{17}$. The first method is to exclude 'switchers' between the treatment and control groups from the sample. If 'switchers' are physicians who are most affected by the reform, and therefore most likely to respond to it, this method will underestimate the true reform impact. The second method is to include 'switchers' in the sample but control for physicians' unobserved, time-invariant characteristics that account for permanent differences among physicians. In so far as these characteristics adequately explain reasons for the 'switch', the method will produce an unbiased estimate of the reform impact. We explore both of these methods in section 6 .

In the lower panel of Table 2, we examine the effect of removing 'switchers' from the sample on our previous results ${ }^{18}$. The most striking result is that the percentage change for exempted services for groups $B$ and $C$ is now significantly smaller than it was in the original sample. In addition, the percentage change for the SRI physicians is now negligible ( $-3 \%$ for both exempted and non-exempted services). These findings underscore the importance of accounting for composition bias in our study. However, the findings also indicate that the composition bias cannot explain all of the observed change in exempted services, as the percentage changes in exempted services for groups $B$ and $C$ remain quite large ( $-27 \%$ and $-24 \%$, respectively).

In Figure 2, we show that the large percentage changes in exempted

\footnotetext{
${ }^{17}$ In the difference-in-difference framework, recent studies that address composition bias include Autor et al. (2003), Autor and Scarborough (2004), Beegle and Stock (2003), Mas (2004), and Ray and Saez (2004).

${ }^{18}$ The 'switchers' include the following groups of physicians: 14 physicians who were SRI in 1997, but not in 1998; 29 physicians who switched from group A in 1997 to SRI in 1998; 97 physicians who switched from group B in 1997 to SRI in 1998; and 58 physicians who switched from group C in 1997 to SRI in 1998.
} 
services for groups $B$ and $C$ do not reflect normal year-to-year fluctuations in physicians' behavior. In this figure, we plot the number of exempted services per physician for each treatment group and the SRI group during the period 1992 to 2004. Included in the sample are physicians who provided some exempted services in at least one year during this period, and to physicians who did not switch their SRI status between 1997 and 1998. The figure shows a significant dip in the number of exempted services per physician for groups $B$ and $C$ in 1998. Moreover, the 1998 dip for groups $B$ and $C$ is the largest change in the number of exempted services per physician over the entire sample period. Furthermore, we find no significant change in the provision of exempted services for physicians in groups $A$ and $S R I$ in 1998, as expected. Figure 3 also shows that the 1998 reform did not have any discernible general equilibrium or spillover effect, as the reduction of exempted services by physicians in groups $B$ and $C$ was not picked up by physicians in group $A$ and the $S R I$ physicians.

Figure 3 provides further evidence of the 1998 reform impact. In this figure, we plot the ratio of exempted to non-exempted services during the same period and for the same group of physicians as in Figure 2 . The figure shows that the exempted services per physicians fell significantly for groups $B$ and $C$ in 1998 not only in absolute value, but also relative to nonexempted services, as is implied by our analysis. On the other hand, we find no significant change in the ratio of exempted to non-exempted services for groups $A$ and $S R I$ in 1998.

\section{Empirical Strategy}

\subsection{Identification}

One way to improve our unconditional estimates of the impact of 1998 reform in the previous section is to control for physicians' characteristics, and use the least squares method to estimate the following model:

$$
\begin{aligned}
y_{i t}= & \alpha+\beta_{B} \times \text { group }_{i}+\beta_{C} \times \text { group }_{i}+\delta \times \text { year } 1998_{i t} \\
& +\gamma_{B} \times \text { year } 1998_{i t} \times \text { group }_{i}+\gamma_{C} \times \text { year } 1998_{i t} \times \text { group }_{i} \\
& +\theta x_{i t}+\varepsilon_{i t}
\end{aligned}
$$


where $y_{i t}$ indicates the number of medical services provided by physician $i$ in year $t$; group $B_{i}$ is an indicator for physicians in group $B$ and group $C_{i}$ is an indicator for physicians in group $C$ (the omitted category is group A); year $1998_{i t}$ denotes observations in year 1998; $x_{i t}$ is a vector of physician's characteristics (age and its square, gender, medical specialty, and geographic location of practice); and $\varepsilon_{i t}$ is the error term.

The impact of the 1998 reform for physicians in group $A$ is measured by $\delta$, for physicians in group $B$ by $\delta+\gamma_{B}$, and for physicians in group $C$ by $\delta+\gamma_{C}$. In this approach, known in the literature as the difference method, the impact of the 1998 reform is identified by comparing medical services provided by physicians in each treatment group before and after the reform, and to attribute the change in medical services to the 1998 reform.

There are at least three reasons for why the difference method can fail to identify the true causal impact of the reform in our study. The first reason is that we can fail to account for all variables that can potentially affect the provision of medical services, in addition to the 1998 reform. Two examples of such variables are various government policies and shocks to the physicians' labor market. If these variables affect the provision of services and we omit them from our model, the estimates of $\delta, \delta+\gamma_{B}$, and $\delta+\gamma_{C}$ will not reflect the impact of the 1998 reform but rather the joint impact of the reform and the omitted variables. To address this problem, we use physicians with the SRI status to difference out the impact of the omitted variables. Specifically, we augment model (6) as follows:

$$
\begin{aligned}
y_{i t}= & \alpha+\beta_{B} \times \text { group }_{i}+\beta_{C} \times \text { group }_{i}+\beta_{S} \times \text { group } R I_{i}+ \\
& \delta \times \text { year } 1998_{i t}+\gamma_{B} \times \text { year } 1998_{i t} \times \text { group }_{i}+ \\
& \gamma_{C} \times \text { year } 1998_{i t} \times \text { group }_{i}+\gamma_{S} \times \text { year } 1998_{i t} \times \text { group }_{S} R I_{i} \\
& +\theta x_{i t}+u_{i t}
\end{aligned}
$$

In this model the change in the provision of services by the SRI physicians between 1997 and 1998 is measured by $\delta+\gamma_{S}$. The change should mainly reflect the impact of omitted variables, not the 1998 reform, because the SRI physicians are exempted from the threshold system as we mentioned earlier. By subtracting $\delta+\gamma_{S}$ from $\delta, \delta+\gamma_{B}$, and $\delta+\gamma_{C}$, we obtain the impact of the 1998 reform purged from the effect of the omitted variables: $-\gamma_{S}$ for physicians in group $A, \gamma_{B}-\gamma_{S}$ for physicians in group $B$, and $\gamma_{C}-\gamma_{S}$ 
for physicians in group $C$. This strategy, known in the literature as the difference-in-difference method, relies on the assumption that any omitted variables affect physicians in the SRI control group and physicians in the treatment groups $A, B$, and $C$ in a similar way.

The second reason for why we can fail to identify the impact of the reform is that physicians choose how many medical services to provide and of what type. Therefore the assignment of physicians to the treatment groups is not random. In so far as the assignment is based on the observable characteristics of physicians that we can control for, we have no reasons to worry. But if physicians chose their provision of medical services in 1997 anticipating the 1998 reform, our estimates of the impact of the 1998 reform will be biased. For example, if physicians anticipated that the 1998 reform will eliminate the exemption status for certain services, we expect that physicians would attempt to provide more than the usual number of these services in 1997, and our estimates of the reform impact will be biased downward. To deal with the problem, we use information on the type and number of medical services provided in 1996 to assign physicians to the treatment groups. The assignment based on the 'taxable' billings in 1996 should be correlated with the assignment based on the 'taxable' billings in 1997, but it is unlikely that physicians chose what services to provide in 1996 anticipating the 1998 reform.

The third reason to worry about identifying the impact of the 1998 reform is that the assignment of physicians to the treatment groups may be imprecise. This could be the case if the actual and desired choices of medical services are not identical because physicians make optimization errors or there are constraints that limit their choices. Our approach to this problem is, again, to instrument the assignment to the treatment groups in 1997 by using the type and number of medical services provided in 1996.

\subsection{Econometric Methods}

\section{Accounting for the discrete, non-negative dependent variable}

The least squares may not be a preferable estimation method when we have a discrete, non-negative dependent variable, as is the case with the number of exempted and non-exempted services in our study. A commonly used model for the discrete or count data is the Poisson model. The contribu- 
tion to the likelihood of the $i t^{t h}$ observation of a Poisson-distributed random variable $Y$ is:

$$
f\left(y_{i t}\right)=\operatorname{Pr}\left(Y_{i t}=y_{i t}\right)=\left[\lambda_{i t}^{y_{i t}} \exp \left(-\lambda_{i t}\right)\right] / y_{i t} !
$$

The density of $Y_{i t}$ is made conditional on the explanatory variables by parameterizing the mean $\lambda_{i t}$ as $\ln \lambda_{i t}=\rho x_{i t}$, where $x_{i t}$ includes all exogenous variables in model (7).

The unattractive feature of the Poisson model is that the mean and variance of the Poisson-distributed variable are identical, while many count data are characterized by 'over-dispersion', meaning that the variance exceeds the mean.

Over-dispersion in count data may be due to unobserved individual heterogeneity. If this heterogeneity is modeled using the gamma distribution, we have the negative binomial model. The density of the negative binomial is derived by adding an error term to the conditional mean of the Poisson as $\ln$ $\lambda_{i t}=\rho x_{i t}+\epsilon$, where $\exp (\epsilon)$ follows a gamma distribution with mean one and variance $\alpha$. The introduction of the extra parameter $\alpha$ permits the mean to differ from the variance. In particular, $\operatorname{Var}\left[y_{i t}\right]=E\left[y_{i t}\right]\left(1+\alpha E\left[y_{i t}\right]\right)$. When $\alpha=0$, the model reduces to the Poisson model. Therefore, a convenient test of over-dispersion in the context of the Poisson model is a $t$-test on the statistical significance of the estimated value of $\alpha$.

\section{Accounting for excess zeros in the dependent variable}

Two models are commonly employed in the literature to account for excess zeros in count dependent variables: the zero-inflated model and the two-part model.

The zero-inflated model distinguishes between physicians who provide no medical services of particular type by their own choice (potential providers) and those who provide none of these services because they lack adequate knowledge, equipment, etc. (non-providers). The model consists of two parts: (1) a splitting model, which estimates the probability that a physician is one of two types: a non-provider or a potential provider; and (2) a Poisson/Negative Binomial model for the provision of medical services by potential providers.

To illustrate, let $q_{i}$ be the probability that a physician $i$ is a non-provider; let $f()$ be the Poisson/Negative Binomial density function; and let $y_{i}$ be 
the number of medical services provided by physician $i$. Then, the sample densities for provision of medical services are as follows:

$$
\begin{aligned}
& \operatorname{prob}\left(y_{i}=0\right)=q_{i}+\left(1-q_{i}\right) f\left(y_{i}=0\right) \\
& \operatorname{prob}\left(y_{i}=j>0\right)=\left(1-q_{i}\right) f\left(y_{i}=j\right)
\end{aligned}
$$

When we can identify potential providers and non-providers, so that $q_{i}$ is either 0 or 1 , the zero-inflated model reduces to a simple Poisson/Negative Binomial model. As discussed earlier, we exploit information on the provision of exempted services over the 1992 to 2004 period to identify potential providers and non-providers, and we then use the sample of potential providers to estimate simple Poisson and Negative Binomial models throughout most of our analysis.

The two-part model, on the other hand, decomposes the medical services into two observed random components: " $y_{i}>0$ " and " $y_{i} \mid y_{i}>0$ " and then specifies probability model for each part. The two-part model is usually estimated by maximum likelihood methods, estimating each part of the model separately. In our case, we use the Probit model for " $y_{i}>0$ " part and the negative binomial model for " $y_{i} \mid y_{i}>0$ " part. Again, by identifying potential providers and non-providers, the two-part model can be reduced to the " $y_{i} \mid y_{i}>0$ " part only (a Poisson or Negative Binomial model in the sample of potential providers).

\section{Results}

\subsection{Medical Services Exempted in 1997}

We start our analysis with medical services that were exempted from the threshold system in 1997 but turned into non-exempted services after the 1998 reform. According to Proposition 1, the 1998 reform should have no impact on the provision of exempted services for physicians in group $A$, a negative impact for physicians in group $C$, and a priori ambiguous impact for physicians in group $B$.

To examine these predictions, we estimate parameters in equation (7) using three models discussed earlier: the ordinary least squares, the Poisson, and the negative binomial model. The results are presented in Table 3. The 
upper panel of the table presents the simple difference estimates, while the lower panel presents the difference-in-difference estimates.

The difference estimates indicate a negative, large and statistically significant impact for physicians in groups $B$ and $C$ in all three models. The difference-in-difference estimates strongly reconfirm these findings. For physicians in group $A$, both the difference and difference-in-difference estimates indicate a negative impact that is also statistically significant in the least squares and negative binomial models. However, the impact for group $A$ is relatively small (in absolute value) compared to the impact for physicians in groups $B$ and $C$. The estimated $\alpha$ is 5.08 with standard error of 0.11 , indicating over-dispersion in the number of exempted services in our sample.

These results are largely consistent with the empirical predictions stated in Proposition 1: a relatively small impact for group $A$; a large, negative impact for group $C$; and an impact for group $B$ that is consistent with strong own-price and income elasticities of hours of work and a weak crossprice elasticity.

While promising, these results must be considered preliminary for at least four reasons, as we discussed earlier: (1) they may reflect composition bias and not a genuine change in physicians' behavior; (2) the assignment of physicians to the treatment groups may be imprecise; (3) excluding physicians who provided no exempted services in any year during the 1992 to 2004 period may not be the correct way to account for excess zeros in the number of exempted services; and (4) the observed changes may reflect normal yearto-year fluctuations in physicians' behavior. We examine robustness of our results to these issues in Table 4.

Column (1) presents the results obtained from the negative binomial model ${ }^{19}$ in the sample that excludes physicians who switched their SRI status between 1997 and 1998. The results clearly show the importance of composition bias in our study: the estimated impact for physicians in groups $B$ and $C$ represents only about half of the estimated impact presented in Table 3. However, the estimated impact for these two groups remains relatively large and statistically significant. This finding verifies our earlier conjecture that the composition bias cannot explain all of the observed effect for physicians in groups $B$ and $C$. On the other hand, the impact for physicians in the

\footnotetext{
${ }^{19}$ These results are qualitatively identical in the least squares and Poisson models. The estimated $\alpha$ is 5.23 with standard error of 0.12 , again indicating over-dispersion in the number of exempted services.
} 
SRI group is negligible and not statistically significant, compared to a large, positive, and statistically significant impact in Table 3 . As a consequence, the difference-in-difference estimate of the impact for physicians in group A is now very small and not statistically significant. These results are entirely consistent with our earlier findings of a small effect for group $A$ and a negative and large impact for groups $B$ and $C$.

An alternative way to account for composition bias is by including physician fixed effects that control for permanent differences among physicians but include both 'switchers' and 'non-switchers' in the sample ${ }^{20}$. The results obtained from the fixed-effect negative binomial model ${ }^{21}$ are presented in column (2) of Table 4. The difference estimates indicate a negative and statistically significant impact for all groups of physicians, including the SRI control group. The difference-in-difference estimates strongly confirm these results for groups $B$ and $C$, but they indicate positive and statistically significant impact for group $A$. However, the impact for group $A$ remains relatively small (in absolute value) compared to the impact for groups $B$ and $C$.

We next examine the robustness of our findings with respect to the assignment of physicians to the treatment groups. As discussed before, the assignment based on 1997 billings may yield biased estimates if physicians sort into different groups based on their anticipation of the 1998 reform, or if they make optimization errors such that their actual and desired choices deviate from each other. In column (3) we present results obtained from the negative binomial model estimates when the assignment to treatment groups is based on physicians' billings in 1996 instead of 1997. Given our earlier findings regarding the importance of composition bias, we exclude "SRI switchers" from the sample. In comparison to estimates presented in column (1), the estimated impact for group $B$ is now relatively larger and for group $C$ relatively smaller. However, the estimated impact for both groups remains negative, statistically significant and large compared to the small and statistically insignificant impact for group $A$.

\footnotetext{
${ }^{20}$ The results are qualitatively identical if we restrict the sample to 'non-switchers'.

${ }^{21}$ The results obtained using the fixed-effect Poisson model are qualitatively identical. The fixed-effect least squares estimates are not significant for group $C$. However, fixedeffect least squares has the worst fit, as measured by the mean square error (974.81 compared to about 886 for each of the fixed-effect Poisson and fixed-effect negative binomial models).
} 
In column (4), we present the estimates obtained from the zero-inflated negative binomial model in the sample that includes all physicians, regardless of whether they provided exempted services in the 1992-2004 period or not. We continue to exclude the 'SRI switchers' from the sample. Both the difference and difference-in-difference estimates indicate a large and statistically significant impact for physicians in groups $B$ and $C$, and a positive and statistically significant impact for physicians in group $A$. The estimated impact for group $B$ is still substantially larger in absolute value that the impact for group $A$, but the estimated impact for group $C$ is now smaller in absolute value than the impact for group $C^{22}$. On balance, these results reasonably confirm our earlier findings and we conclude that our method of excluding non-providers in the 1992-2004 period does not seriously affect our results compared to models that explicitly model the decision to provide any exempted services.

Lastly, we examined whether the change in provision of exempted services across treatment groups varied between 1996 and 1997 in a similar way as the change between 1997 and 1998. If it did, then our earlier results may represent normal year-to-year fluctuations in physicians' behavior and not behavioral response to the 1998 reform. Our results, obtained using the negative binomial model ${ }^{23}$, are presented in column (5) of Table 4 . The sample used for this table excludes the non-provider physicians and the 'SRI switchers'. Both the difference and difference-in-difference results indicate no statistically significant change in the provision of exempted services for groups $B$ and $C$. Even the point estimates for group $C$ have the 'wrong', positive sign. The estimates for group $A$ are positive and statistically significant. Therefore, we do not observe the same pattern nor the statistical significance for the change in the exempted services between 1996 and 1997 as we did for the change between 1997 and 1998.

\footnotetext{
${ }^{22}$ In the two-part model and the zero-inflated Poisson, the impact for group $A$ does not exceed the impact for group $C$ in absolute value. In terms of the mean square error, the two-part model fares the best (692.89) followed by the zero-inflated Poisson and the zero-inflated negative binomial (about 885 for both models).

${ }^{23}$ The results obtained using the least squares and Poisson models are qualitatively identical. The estimated $\alpha$ of 4.63 is again statistically significant (standard error of 0.10 ).
} 


\subsection{Non-exempted Medical Services}

We now examine medical services that were non-exempted in both 1997 and 1998. According to Proposition 1, the 1998 reform should have no impact on the provision of non-exempted services by physicians in group $A$, a positive impact for physicians in group $C$, and a priori ambiguous impact on physicians in group $B$.

The results are presented in Table 5. The sample excludes non-provider physicians and the 'SRI switchers', where these groups are as defined before. The difference estimates, presented in the upper panel of Table 5, indicate a negative and statistically significant impact for all three treatment groups of physicians. The difference in difference estimates, presented in the lower panel, show than the estimated impact remains negative for most groups and in most models, but this impact is now not statistically significant. The exception to this is the significant and negative difference-in-difference estimate for physicians in group $C$ obtained using the least squares model.

These results are consistent with Proposition 1 for physicians in groups $A$ and $B$. For physicians in group $C$, the finding of no impact is also consistent with Proposition 1 if the cross-price elasticity of hours of work is close to zero.

If we focus on the difference-in-difference point estimate for group $C$, we can see that this estimate is substantially smaller than the point estimates for exempted services ${ }^{24}$. In other words, even if physicians in group $C$ decreased their provision of both exempted and non-exempted services, they decreased their provision of exempted services relatively more than their provision of non-exempted services.

One possible explanation of this result is that physicians in group C responded to the incentives in the 1998 reform not only by changing the type of services they provide but also by decreasing their labor supply. For example, physicians may have imperfect ability to influence types of medical services they provide and the only way to reduce the number of exempted services is to reduce the number of days they work per year. In that case, they would reduce their provision of both exempted and non-exempted services, but if our analysis is correct, we should observe relatively larger reduction in exempted services.

\footnotetext{
${ }^{24}$ Except for the ordinary least squares, but this model is inferior to the Poisson and negative binomial models in terms of fit and because it doesn't account for disrete, nonnegative nature of the dependent variable, as discussed earlier.
} 


\section{Conclusions}

This study analyzes the impact of the 1998 reform to the physicians' threshold system in Ontario, Canada. The 1998 reform turned a large number of exempted medical services into non-exempted services, and we examine whether physicians responded to the reform by changing the composition of services they provide. Our results indicate that physicians with relatively low billings (those below the minimum threshold) did not respond to the reform, while physicians with relatively high billings (those above the minimum threshold using the 1998 reform rules) decreased their provision of exempted services and did not significantly change their provision of non-exempted services.

The heterogeneity in the physicians' response to the 1998 reform is largely consistent with predictions derived from a model of labor supply with nonlinear budget set that has been used extensively in studies of income tax systems. Therefore, it may be fruitful to employ a version of the similar model in analyzing reforms that affected other elements of the threshold system such as threshold levels. The similarity between the threshold system and the income tax system also suggests that many questions related to the impact of the threshold system can be better understood using a large empirical literature on the impact of income tax systems.

Our analysis admittedly takes only first few steps in improving our understanding of the impact of the threshold system on the behavior of physicians. Many questions remain to be answered, including: What is the impact of threshold system on the total billings of physicians? To what extent does the threshold system induce physicians to migrate to jurisdictions that do not employ the system? We plan to tackle these questions in our future research.

Perhaps the most significant question relates to the welfare implications of the threshold system. As we document in this paper, reforms to the threshold system do influence behavior of physicians and can be an effective tool in controlling payments to physicians and managing health care expenditures in general. But ultimately the question is whether such reforms have a negative impact on health outcomes. Gaynor, Rebitzer and Taylor (2004), who find that medical expenditures at the HMO are lower than they would be in the absence of financial incentives, pose the same question in the conclusion of their study.

The policy makers in Ontario and other Canadian provinces have been 
aware of the problem, and have somewhat arbitrarily excluded certain physicians from the threshold system. However, many feel that such policy of excluding a small number of physicians from the system does little to offset the negative impact of the threshold system, because physicians leave for jurisdictions that do not employ the threshold system while physicians who stay have strong incentives to limit their provision of medical services. These questions are important, and future research on these matters should be most useful. 


\section{References}

Autor, D.H.; Donohue, J.J., II; Schwab, S.J., 2003. The Costs of WrongfulDischarge Laws. National Bureau of Economic Research, Inc., NBER Working Papers: 9425.

Autor, D.; Scarborough, D., 2004. Will Job Testing Harm Minority Workers? National Bureau of Economic Research, Inc., NBER Working Papers: 10763.

Beegle, K; Stock, W.A., 2003. The Labor Market Effects of Disability Discrimination Laws. Journal of Human Resources 38(4), 806-59.

Chetty, R.; Saez, E., 2004. Dividend taxes and corporate behavior: evidence from the 2003 dividend tax cut. National Bureau of Economic Research, Inc., NBER Working Papers: 10841.

Dowdall, C.; Ramchandar, L., 1999. The application of physician billing thresholds in Ontario and across Canada, Ontario Medical Review.

Gaynor, M.; Rebitzer J.B.; Taylor L.J., 2001. Incentives in HMOs. National Bureau of Economic Research, Inc., NBER Working Papers: 8522.

Gaynor, M.; Rebitzer J.B.; Taylor L.J., 2004. Physician incentives in health maintenance organizations. Journal of Political Economy 112 (4), 915-931.

Greene, W.H, 1994. Accounting for excess zeros and sample selection in Poisson and negative binomial regression models. Department of Economics Working Paper EC-94-10, Stern School of Business, New York University.

Grootendorst, P.V., 1995. A comparison of alternative models of prescription drug utilization. Health Economics 4, 183-198.

Hausman, J., 1981. Labor Supply. In: How taxes affect economic behavior, eds. H. Aaron and J. Pechman, Washington, DC: Brookings Institution.

Hausman, J., 1985. The econometrics of non-linear budget sets. Econometrica 53, 1255-1282.

Heim, B.T.; Meyer, B.D. 2003. Structural labor supply models when budget sets are nonlinear. Department of Economics, Nortwestern University.

Jones, A.M., 2000. Health econometrics. In: Handbook of Health Economics, Volume 1, eds. A.L. Culyer and J.P. Newhouse.

Mas, A. 2004. Do disappoint pay raises lower productivity? Final offer arbitration and the performance of New Jersey police officers. Manuscript, University of California at Berkeley.

Moffitt, R., 1986. The econometrics of piecewise-linear budget constraints: a survey and exposition of the maximum likelihood method. Journal of Busi- 
ness and Economic Statistics 4(3), 317-328.

Moffitt, R., 1990. The econometrics of kinked budget constraints. Journal of Economic Perspectives 4(2): 119-139. 
Table 1. Descriptive Statistics

Year 1997

\begin{tabular}{|c|c|c|c|c|}
\hline & Group A & Group B & Group C & SRI \\
\hline \multicolumn{5}{|l|}{ Physicians' Characteristics } \\
\hline Age & 49.80 & 48.47 & 48.24 & 48.45 \\
\hline$\%$ Male & 0.78 & 0.91 & 0.94 & 0.99 \\
\hline$\%$ General Practitioner & 0.62 & 0.09 & 0.63 & 0.34 \\
\hline$\%$ Practicing in Toronto & 0.23 & 0.31 & 0.30 & 0.25 \\
\hline \multicolumn{5}{|l|}{ Medical Services per Physician } \\
\hline All medical services & 9,903 & 12,800 & 20,194 & 14,936 \\
\hline Services exempted in 1997 & 281 & 2,032 & 431 & 535 \\
\hline Non-exempted services & 9,622 & 10,768 & 19,763 & 14,401 \\
\hline Observations (Total=6,203) & 5,093 & 321 & 700 & 89 \\
\hline \multirow[t]{3}{*}{ Percentage of total observations } & $82.11 \%$ & $5.17 \%$ & $11.28 \%$ & $1.43 \%$ \\
\hline & \multicolumn{4}{|c|}{ Year 1998} \\
\hline & Group A & Group B & Group C & SRI \\
\hline \multicolumn{5}{|l|}{ Physicians' Characteristics } \\
\hline Age & 50.81 & 50.19 & 49.25 & 48.45 \\
\hline$\%$ Male & 0.78 & 0.91 & 0.94 & 0.94 \\
\hline$\%$ General Practitioner & 0.62 & 0.13 & 0.66 & 0.15 \\
\hline$\%$ Practicing in Toronto & 0.23 & 0.36 & 0.32 & 0.24 \\
\hline \multicolumn{5}{|l|}{ Medical Services per Physician } \\
\hline All medical services & 9,522 & 11,989 & 18,695 & 12,397 \\
\hline Services exempted in 1997 & 265 & 1,332 & 276 & 903 \\
\hline Non-exempted services & 9,257 & 10,657 & 18,419 & 11,494 \\
\hline Observations (Total=6,203) & 5,078 & 224 & 642 & 259 \\
\hline Percentage of total observations & $81.82 \%$ & $3.62 \%$ & $10.37 \%$ & $4.18 \%$ \\
\hline
\end{tabular}

The assignment to physicians' groups is based on the type and number of medical services physicians provided in 1997, and the physicians' SRI status in 1997 and 1998.

Definition of physicians' groups:

A: physicians who were below the threshold level in both 1997 and 1998;

B: physicians who were below the threshold level in 1997, but would be above the threshold level in 1998 if they provided the same type and number of medical services in 1998 as they did in 1997;

C: physicians who were above the threshold level in both 1997 and 1998;

SRI: physicians with the Specialist Retention Initiative status (either full or partial) in 1997 or 1998.

Source: Ontario Health Insurance Plan (OHIP) claims database. 


\section{Table 2. Percentage Change in Medical Services per Physician between 1997 and 1998}

\begin{tabular}{lcccc} 
Including 'SRI Switchers' & & & & \\
& Group A & Group B & Group C & SRI \\
\hline All medical services & $-3.85 \%$ & $-6.33 \%$ & $-7.42 \%$ & $-17.00 \%$ \\
$\quad$ Services exempted in 1997 & $-5.71 \%$ & $-34.45 \%$ & $-35.89 \%$ & $68.77 \%$ \\
Non-exempted services & $-3.80 \%$ & $-1.03 \%$ & $-6.80 \%$ & $-20.19 \%$ \\
& & & & \\
Number of physicians in 1997 (Total=6,203) & 5,093 & 321 & 700 & 89 \\
Number of physicians in 1998 (Total=6,203) & 5,078 & 224 & 642 & 259 \\
\hline
\end{tabular}

\section{Excluding 'SRI Switchers'}

\begin{tabular}{lcccc}
\hline & Group A & Group B & Group C & SRI \\
\hline All medical services & $-3.92 \%$ & $-10.02 \%$ & $-8.83 \%$ & $-3.34 \%$ \\
$\quad$ Services exempted in 1997 & $-1.23 \%$ & $-27.28 \%$ & $-23.65 \%$ & $-3.15 \%$ \\
$\quad$ Non-exempted services & $-3.99 \%$ & $-7.27 \%$ & $-8.56 \%$ & $-3.35 \%$ \\
Number of physicians (Total=6,005) & 5,064 & 224 & 642 & 75 \\
\hline \hline
\end{tabular}

'Switchers' are physicians who changed their SRI status between 1997 and 1998.

The assignment to physicians' groups is based on the type and number of medical services physicians provided in 1997 , and the physicians' SRI status in 1997 and 1998.

Definition of physicians' groups:

A: physicians who were below the threshold level in both 1997 and 1998;

B: physicians who were below the threshold level in 1997, but would be above the threshold level in 1998 if they provided the same type and number of medical services in 1998 as they did in 1997;

C: physicians who were above the threshold level in both 1997 and 1998;

SRI: physicians with the Specialist Retention Initiative status (either full or partial) in 1997 or 1998.

Source: Ontario Health Insurance Plan (OHIP) claims database. 
Table 3. The Impact of the 1998 Reform on the Provision of Exempted Medical Services

Dependent variable $=$ Number of Exempted Medical Services

(1)

(2)

(3)

\begin{tabular}{|c|c|c|c|}
\hline & $\begin{array}{c}\text { Least } \\
\text { Squares }\end{array}$ & Poisson & $\begin{array}{l}\text { Negative } \\
\text { Binomial }\end{array}$ \\
\hline \multicolumn{4}{|l|}{ Difference Estimates } \\
\hline Group A & $\begin{array}{c}-14.29 * \\
(-1.79)\end{array}$ & $\begin{array}{c}-0.055^{*} \\
(-1.89)\end{array}$ & $\begin{array}{l}-0.015 \\
(-0.36)\end{array}$ \\
\hline Group B & $\begin{array}{c}-790.28 * * * \\
(-6.65)\end{array}$ & $\begin{array}{c}-0.538 * * * \\
(-7.84)\end{array}$ & $\begin{array}{c}-0.428 * * * \\
(-3.86)\end{array}$ \\
\hline Group C & $\begin{array}{c}-146.56 * * * \\
(-3.56)\end{array}$ & $\begin{array}{c}-0.402 * * * \\
(-4.33)\end{array}$ & $\begin{array}{c}-0.741 * * * \\
(-3.33)\end{array}$ \\
\hline Group SRI & $\begin{array}{c}244.95 * * * \\
(3.29)\end{array}$ & $\begin{array}{l}0.126 \\
(0.99) \\
\end{array}$ & $\begin{array}{c}0.289 * * \\
(2.28)\end{array}$ \\
\hline \multicolumn{4}{|c|}{$\begin{array}{l}\text { Difference-in-Difference } \\
\text { Estimates }\end{array}$} \\
\hline Group A & $\begin{array}{c}-259.24 * * * \\
(-3.46)\end{array}$ & $\begin{array}{l}-0.180 \\
(-1.39)\end{array}$ & $\begin{array}{c}-0.305 * * \\
(-2.23)\end{array}$ \\
\hline Group B & $\begin{array}{c}-1035.23 * * * \\
(-7.04)\end{array}$ & $\begin{array}{c}-0.664 * * * \\
(-4.59)\end{array}$ & $\begin{array}{c}-0.717 * * * \\
(-4.11)\end{array}$ \\
\hline Group C & $\begin{array}{c}-391.51 * * * \\
(-4.33)\end{array}$ & $\begin{array}{c}-0.527 * * * \\
(-3.25)\end{array}$ & $\begin{array}{c}-1.031 * * * \\
(-3.92)\end{array}$ \\
\hline $\begin{array}{l}\alpha \\
\text { (standard error) }\end{array}$ & - & - & $\begin{array}{c}5.08 \\
(0.11) \\
\end{array}$ \\
\hline Observations & 12,406 & 12,406 & 12,406 \\
\hline \# physicians & 6,203 & 6,203 & 6,203 \\
\hline
\end{tabular}

Numbers in parentheses are t-ratios for column (1) and z-ratios for columns (2)-(3). Standard errors are robust and adjusted for clustering on physicians' identification numbers. Other variables in the models include: a quadratic in age, a gender indicator, 7 regional indicators, and 33 indicators for medical specialties. The sample includes physicians who were present in both 1997 and 1998 and physicians who provided some exempted services in at least one of the years from 1992 to 2004 . *** significance at 0.01 level; ** at 0.05 ; and * at 0.10 . 
Table 4. Robustness checks

Dependent variable $=$ Number of Exempted Medical Services

\begin{tabular}{|c|c|c|c|c|c|}
\hline Specification & $\begin{array}{c}\text { Excluding } \\
\text { 'Switchers' } \\
(1)\end{array}$ & $\begin{array}{c}\text { Fixed } \\
\text { Physician } \\
\text { Effects } \\
(2) \\
\end{array}$ & $\begin{array}{l}\text { Assignment } \\
\text { based on } \\
1996 \text { billings } \\
\text { (3) }\end{array}$ & $\begin{array}{c}\text { Including } \\
\text { All } \\
\text { Physicians } \\
(4) \\
\end{array}$ & $\begin{array}{c}1996-97 \\
\text { change } \\
(5)\end{array}$ \\
\hline \multicolumn{6}{|l|}{ Difference } \\
\hline \multicolumn{6}{|l|}{ Estimates } \\
\hline Group A & $\begin{array}{l}0.010 \\
(0.23)\end{array}$ & $\begin{array}{c}-0.014 * * * \\
(-11.67)\end{array}$ & $\begin{array}{l}-0.006 \\
(-0.15)\end{array}$ & $\begin{array}{c}0.028 * * * \\
(25.98)\end{array}$ & $\begin{array}{c}0.185^{* * * *} \\
(5.84)\end{array}$ \\
\hline Group B & $\begin{array}{c}-0.382 * * * \\
(-4.51)\end{array}$ & $\begin{array}{c}-0.319 * * * \\
(-132.40)\end{array}$ & $\begin{array}{c}-0.571 * * * \\
(-3.38)\end{array}$ & $\begin{array}{c}-0.371 * * * \\
(-168.63)\end{array}$ & $\begin{array}{l}-0.082 \\
(-1.60)\end{array}$ \\
\hline Group C & $\begin{array}{c}-0.573 * * \\
(-2.18)\end{array}$ & $\begin{array}{c}-0.270 * * * \\
(-85.60)\end{array}$ & $\begin{array}{c}-0.229 * * * \\
(-3.11)\end{array}$ & $\begin{array}{c}-0.162 * * * \\
(-57.40)\end{array}$ & $\begin{array}{c}0.183 * * \\
(2.28)\end{array}$ \\
\hline Group SRI & $\begin{array}{l}-0.005 \\
(-0.17)\end{array}$ & $-0.086 * * *$ & $\begin{array}{l}-0.002 \\
(-0.07)\end{array}$ & $\begin{array}{c}-0.094 * * * \\
(-14.60)\end{array}$ & $\begin{array}{r}0.024 \\
(0.32)\end{array}$ \\
\hline \multicolumn{6}{|l|}{ Diff-in-Diff } \\
\hline Group A & $\begin{array}{l}0.015 \\
(0.28)\end{array}$ & $\begin{array}{c}0.072 * * * \\
(10.67)\end{array}$ & $\begin{array}{l}-0.004 \\
(-0.08)\end{array}$ & $\begin{array}{c}0.122 * * * \\
(18.76)\end{array}$ & $\begin{array}{c}0.161 * * \\
(1.99)\end{array}$ \\
\hline Group B & $\begin{array}{c}-0.377 * * * \\
(-4.18)\end{array}$ & $\begin{array}{c}-0.233 * * * \\
(-33.16)\end{array}$ & $\begin{array}{c}-0.569 * * * \\
(-3.31)\end{array}$ & $\begin{array}{c}-0.278 * * * \\
(-40.85)\end{array}$ & $\begin{array}{l}-0.106 \\
(-1.17)\end{array}$ \\
\hline Group C & $\begin{array}{c}-0.568 * * \\
(-2.15)\end{array}$ & $\begin{array}{c}-0.184 * * * \\
(-25.18)\end{array}$ & $\begin{array}{c}-0.227 * * * \\
(-2.87)\end{array}$ & $\begin{array}{c}-0.068 * * * \\
(-9.72)\end{array}$ & $\begin{array}{l}0.159 \\
(1.45)\end{array}$ \\
\hline Observations & 12,010 & 12,406 & 12,010 & 36,722 & 12,010 \\
\hline \# physicians & 6,005 & 6,203 & 6,005 & 18,361 & 6,005 \\
\hline
\end{tabular}

Models (1), (3) and (5) are the negative binomial models; model (2) is the fixed-effect negative binomial model, and model (4) is the zero-inflated negative binomial model. Numbers in parentheses are z-ratios. Standard errors are robust and adjusted for clustering on physicians' identification numbers, except in model (3). Other variables in models (1)-(3) and (5) include: a quadratic in age, a gender indicator, 7 regional indicators, and 33 indicators for medical specialties. Other variables in model (4) include: a quadratic in age, a gender indicator, an indicator for the Toronto planning region, and an indicator for general practitioners. All models include only physicians who were present in both 1997 and 1998; models (1), (3), and (5) exclude 'switchers'; and all models except (4) exclude physicians who provided no exempted services in any of the years 1992 to 2004 . *** significance at 0.01 level; ** at 0.05 ; and $*$ at 0.10 . 
Table 5. The Impact of the 1998 Reform on the Provision of Non-Exempted Services

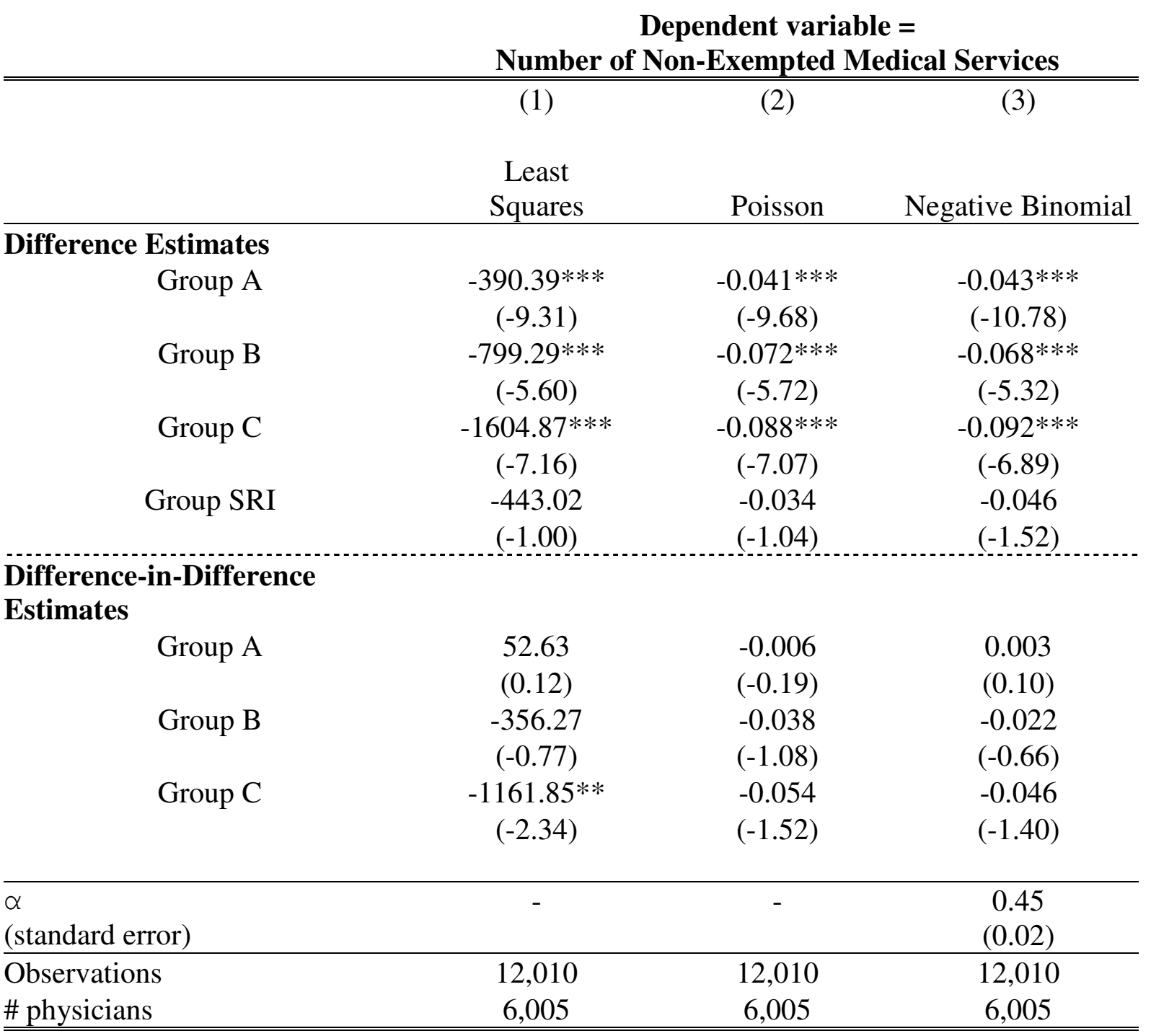

Numbers in parentheses are t-ratios for column (1) and z-ratios for columns (2)-(3). Standard errors are robust and adjusted for clustering on physicians' identification numbers. Other variables in the models include: a quadratic in age, a gender indicator, 7 regional indicators, and 33 indicators for medical specialties. The sample includes physicians who were present in both 1997 and 1998, physicians who provided some exempted services in at least one of the years 1992 to 2004, and physicians who do not switch their SRI status between 1997 and 1998. *** significance at 0.01 level; $* *$ at 0.05 ; and $*$ at 0.10 . 
Appendix Table 1. Threshold Reduction System in Ontario, 1991 - 2005

\begin{tabular}{|c|c|c|c|c|c|}
\hline Effective Date & Applicability & \begin{tabular}{l}
\multicolumn{1}{c}{$1 / 3$} \\
reduction \\
threshold
\end{tabular} & $\begin{array}{l}\quad 2 / 3 \\
\text { reduction } \\
\text { threshold }\end{array}$ & $\begin{array}{c}3 / 4 \\
\text { reduction } \\
\text { threshold }\end{array}$ & Exempted Services \\
\hline April 1, 1991 & All physicians & $\$ 400,000$ & $\$ 475,000$ & - & Technical Fees \\
\hline October 1, 1992 & All physicians & $\$ 402,000$ & $\$ 477,000$ & - & Technical Fees \\
\hline April 1, 1993 & All physicians & $\$ 404,000$ & $\$ 479,750$ & - & Technical Fees \\
\hline April 1, 1996 & By Specialty & \multicolumn{3}{|c|}{ Specialty specific* } & $\begin{array}{l}\text { Technical Fees, selected } \\
\text { professional fees }\end{array}$ \\
\hline January 1, 1997 & $\begin{array}{l}\text { GPs } \\
\text { Specialists }\end{array}$ & $\begin{array}{l}\$ 300,000 \\
\$ 380,000\end{array}$ & $\begin{array}{l}\$ 337,500 \\
\$ 417,500\end{array}$ & $\begin{array}{l}\$ 412,500 \\
\$ 492,500\end{array}$ & No change \\
\hline April 1, 1998 & $\begin{array}{l}\text { GPs } \\
\text { Specialists }\end{array}$ & $\begin{array}{l}\text { No change } \\
\text { No change }\end{array}$ & $\begin{array}{l}\text { No change } \\
\text { No change }\end{array}$ & $\begin{array}{l}\text { No change } \\
\text { No change }\end{array}$ & $\begin{array}{l}\text { Changes to } 1996 \text { exempted } \\
\text { technical fees and selected } \\
\text { professional fees }\end{array}$ \\
\hline April 1, 1999 & $\begin{array}{l}\text { GPs } \\
\text { Specialists }\end{array}$ & $\begin{array}{l}\$ 320,000 \\
\$ 400,000\end{array}$ & $\begin{array}{l}\$ 345,000 \\
\$ 425,000\end{array}$ & $\begin{array}{l}\$ 370,000 \\
\$ 450,000\end{array}$ & No change \\
\hline April 1, 2000 & $\begin{array}{l}\text { GPs } \\
\text { Specialists }\end{array}$ & $\begin{array}{l}\$ 330,000 \\
\$ 410,000\end{array}$ & $\begin{array}{l}\$ 355,000 \\
\$ 435,000\end{array}$ & $\begin{array}{l}\$ 380,000 \\
\$ 460,000\end{array}$ & No change \\
\hline April 1, 2002 & All physicians & - & $\$ 455,000$ & - & $\begin{array}{l}\text { Additional after-hours non- } \\
\text { elective hospital services, selected } \\
\text { acute care hospital in-patient } \\
\text { services, selected critical care } \\
\text { services }\end{array}$ \\
\hline
\end{tabular}

April 1, $2005 \quad$ All physicians The payment threshold reduction eliminated

Professional fees are fees for medical services rendered by physicians, and technical fees are fees for services rendered by physicians' assistants. Source: Dowdall and Ramchandar (1999).

* For details, see Dowdall and Ramchandar (1999). 


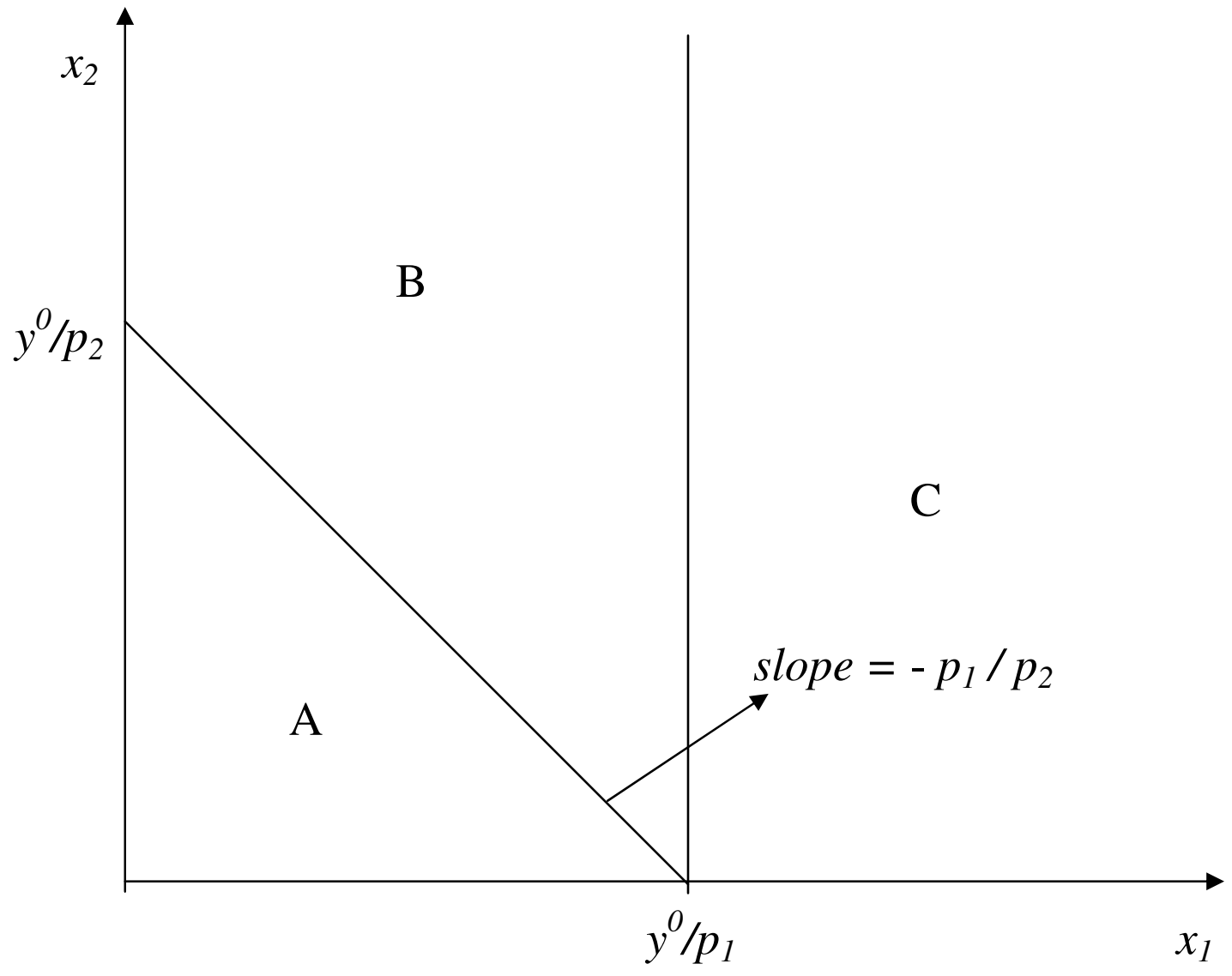

Figure 1 


\section{Exempted Services Per Physician \\ 1992 - 2004*}

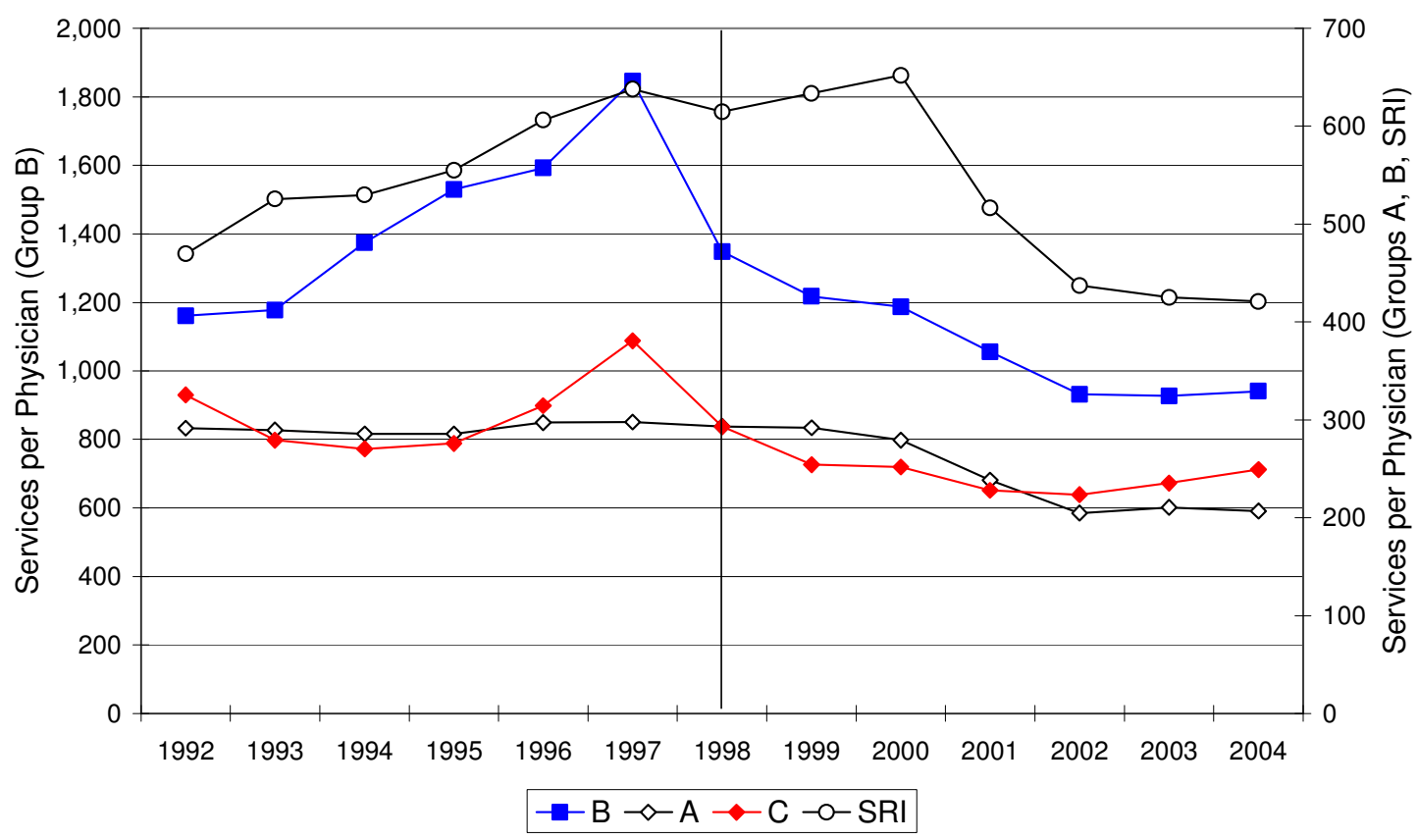

Figure 2

* The sample includes physicians who provided some exempted services in at least one of the years 1992 to 2004 and physicians who did not switch their SRI status between 1997 and 1998. The mean (standard deviation) of the number of physicians in group A over the sample period is 4,846 (265); in group B: 220(5); in group C: 633 (11); and in the SRI group: 74 (2). 
Ratio of Exempted to Non-Exempted Services Per Physician $1992-2004^{\star}$

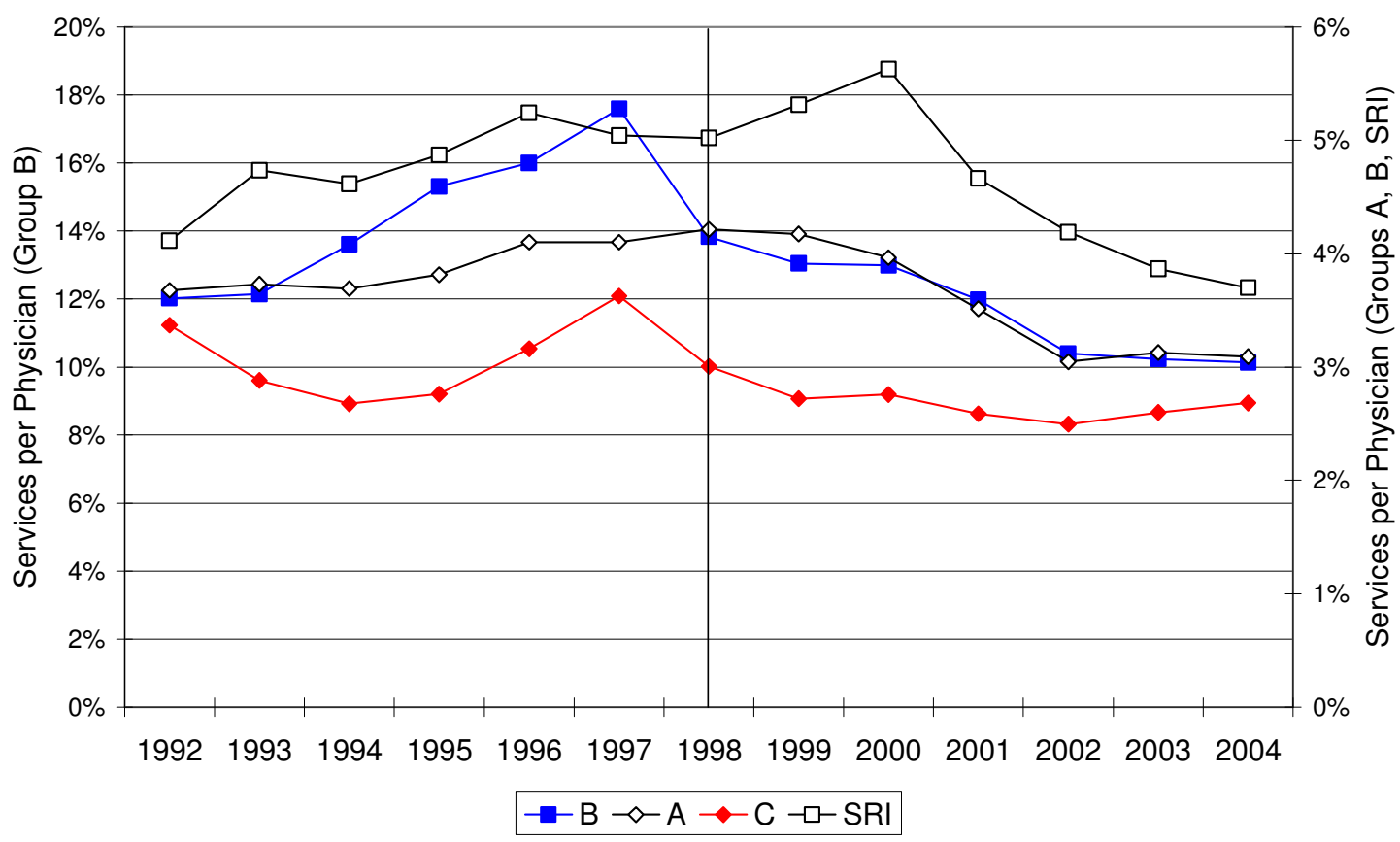

\section{Figure 3}

* The sample includes physicians who provided some exempted services in at least one of the years 1992 to 2004 and physicians who did not switch their SRI status between 1997 and 1998. The mean (standard deviation) of the number of physicians in group A over the sample period is 4,846 (265); in group B: 220(5); in group C: 633 (11); and in the SRI group: 74 (2). 